Chronic Obstructive Pulmonary Diseases: Journal of the COPD Foundation

\author{
Original Research
}

\title{
Risk Factors for Pneumonia and the Effect of the Pneumococcal Vaccine in Patients With Chronic Airflow Obstruction
}

Kazuyoshi Kurashima, MD, $\mathrm{PhD}^{1}$ Yotaro Takaku, $\mathrm{MD}^{1}$ Keitaro Nakamoto, $\mathrm{MD}^{1}$ Tetsu Kanauchi, $\mathrm{MD}^{2}$

Noboru Takayanagi, $\mathrm{MD}^{1}$ Tsutomu Yanagisawa, $\mathrm{MD}^{1}$ Yutaka Sugita, $\mathrm{MD}^{1}$ Ryuichiro Araki, $\mathrm{MD}^{3}$

\section{Abstract}

Background: To evaluate the risk factors for pneumonia and the efficacy of the pneumococcal polysaccharide vaccine (PPV) in patients with chronic airflow obstruction.

Methods: We retrospectively studied the risk factors for pneumonia in 820 consecutive patients with chronic obstructive pulmonary disease (COPD) $(n=509)$ and patients with asthma-COPD overlap syndrome (ACOS) $(n=311)$. The effects of asthma, age, smoking history, chronic sputum, use of inhaled corticosteroids, percent predicted forced vital capacity (\%FVC), percent predicted forced expiratory volume in 1 second (\%FEV ${ }_{1}$ ), body mass index (BMI), computed tomography (CT)-diagnosed emphysema, and the pneumococcal vaccination on the frequency of pneumonia were assessed.

Results: There was no difference in the frequency of pneumonia in patients with COPD and those with ACOS. In a univariate analysis, age $(p=0.031), \% F V C(p<0.001), \% F_{1}(p<0.001)$, BMI $(p=0.003)$, the presence of emphysema $(p<0.001)$ and a history of vaccination with the PPV $(p=0.034)$ were associated with the frequency of pneumonia. A multivariate analysis identified low BMI, the presence of emphysema and the absence of a pneumococcal vaccination as independent risk factors. The combination index of these factors, the BOVE index, which is calculated from low BMI $\left(<22 \mathrm{~kg} / \mathrm{m}^{2}\right)$, low $\% \mathrm{FEV}_{1}(<60 \%)$, vaccination history and emphysema was associated with the overall frequency of pneumonia.

Conclusions: The index of multidimensional risk factors is useful to predict the frequency of pneumonia in patients with chronic airflow obstruction. The pneumococcal vaccination was associated with significantly lower incidence of pneumonia.

\begin{abstract}
Abbreviations: pneumococcal polysaccharide vaccine, PPV; chronic obstructive pulmonary disease, COPD; asthma-COPD overlap syndrome, ACOS; percent predicted forced vital capacity, \%FVC; percent predicted forced expiratory volume in 1 second, \%FEV $\mathbf{1}$; body mass index, BMI; community-acquired pneumonia, CAP; chronic airflow obstruction, CAO; computed tomography, CT; high resolution computed tomography, HRCT; pulmonary function tests, PFTs; standard deviation, SD; inhaled corticosteroids, ICSs

Funding Support: None

Date of Acceptance: January 15, 2016

Citation: Kurashima K, Takaku Y, Nakamoto K, et al. Risk factors for pneumonia and the effect of the pneumococcal vaccine in patients with chronic airflow obstruction. Chronic Obstr Pulm Dis (Miami). 2016;3(3):610-619. doi: http://dx.doi.org/10.15326/ jcopdf.3.3.2015.0167
\end{abstract}

1 Respiratory Medicine, Saitama Cardiovascular and Respiratory Center, Kumagaya City, Saitama, Japan

2 Radiology, Saitama Cardiovascular and Respiratory Center, Kumagaya City, Saitama, Japan

3 Community Health Science Center, Saitama Medical University, Moroyama-machi, Saitama, Japan

\section{Address correspondence to:}

Kazuyoshi Kurashima, MD, PhD

Department of Respiratory Medicine, Saitama Cardiovascular and Respiratory Center

Itai 1696, Kumagaya City

Saitama 360-0197, Japan

Phone: 81-49-223-8638, Fax: 81-49-223-8638,

E-mail: kurashima.kazuyoshi@pref.saitama.lg.jp 
Keywords:

COPD; asthma; pneumonia; pneumonia vaccine; risk factor

\section{Introduction}

Patients with chronic obstructive pulmonary disease (COPD) are at a greater risk of pneumonia than the general population. ${ }^{1}$ In these patients, communityacquired pneumonia (CAP) frequently leads to hospital admission and increased mortality. Age, the severity of airflow limitation, low body mass index (BMI) and a history of pneumonia are reported to be the risk factors for pneumonia in patients with COPD. ${ }^{2,3}$ However, a significant proportion of patients with COPD have features of asthma and the differential diagnosis of COPD and asthma-COPD overlap syndrome (ACOS) is sometimes difficult. ${ }^{4-8}$ There is limited knowledge about the risk factors for pneumonia in patients with chronic airflow obstruction (CAO) including COPD and ACOS.

Streptococcus pneumoniae is the most common cause of CAP in patients with COPD; it accounts for up to $43 \%$ of CAP cases. ${ }^{9}$ The 23 -valent pneumococcal polysaccharide vaccine (PPV) has been proven to have a protective effect against pneumococcal pneumonia in immunocompetent adults, ${ }^{10}$ however, there is only limited evidence on the efficacy of the vaccination in patients with chronic illness or COPD. ${ }^{11-15}$ Furthermore, a double blind-control study is not ethically possible in Japan because the COPD guidelines recommend the use of the PPV. ${ }^{16-18}$

We previously reported the clinical outcomes of patients with COPD, ACOS and other patients with CAO. ${ }^{19}$ Using the data of these patients, we performed a retrospective cohort study to evaluate the risk factors for CAP including the presence of asthma, the presence of computed tomography (CT)-diagnosed emphysema and pneumococcal vaccination in patients with COPD and ACOS.

\section{Methods}

\section{Patients}

This was a retrospective cohort study. The study was approved by the institutional review board of the Saitama Cardiovascular and Respiratory Center (IRB No. 2012001), and informed consent was not required.

We previously reported the clinical outcomes of 1272 consecutive patients with CAO who presented to the Saitama Cardiovascular and Respiratory Center (a tertiary referral center with 155 beds for respiratory disease) in Saitama, Japan, from 2000 to 2011. We first screened all 1960 patients who showed airflow limitations that were not fully reversible (Figure 1). CAO was defined as a forced expiratory volume in 1 second $\left(F^{\prime} V_{1}\right)$ to forced vital capacity (FVC) ratio of $<0.7$ after the use of bronchodilator throughout the observation period. In the present study we performed sub-analyses for 509 patients with COPD and 311 patients with ACOS who could be followed for more than 1 year. The definitions of COPD and ACOS have been previously described. $^{13}$ In brief, criteria for the diagnosis of COPD included CAO and $\geq 10$ pack years of smoking without other respiratory complications documented by medical history, physical examination and high resolution computed tomography (HRCT). Criteria for the diagnosis of ACOS included CAO, medical history of asthma, a post bronchodilator increase in $\mathrm{FEV}_{1}$ of $>12 \%$ and $200 \mathrm{ml}$, and evidence of at least 1 of the following: sputum eosinophilia ( $>3 \%$ ) or increased exhaled nitric oxide (>30ppb) or evidence of atopy. All of the patients who were entered in the present study were examined by HRCT. In patients who received a pneumococcal vaccine, the start of the observation period was defined as the time of vaccine administration. In those patients without the vaccine we started the observation period when the initial diagnosis was made. The explanatory variables for pneumonia and other demographic data were obtained within 3 months of the start of the observation period. We asked every patient about his/ her vaccination status at the start and then once a year during the observation period. Patients were followed until March 2012 or until death or loss to follow-up before March 2012. The frequency of CAP throughout the observation period was calculated. The diagnosis of pneumonia was based on clinical symptoms (cough, sputum or fever), the increased serum level of $\mathrm{C}$-reactive protein, and the appearance of a new infiltration on a chest X-ray. Doctor-diagnosed aspiration pneumonia was excluded in this study.

\section{High Resolution Computed Tomography}

HRCT scans were performed in full inspiration with a HiSpeed Advantage CT scanner (GE Medical Systems, Milwaukee, Wisconsin) with the following parameters: slice thickness, $1 \mathrm{~mm}$; scanning time, 1 second; voltage $140 \mathrm{kV}$, tube current $200 \mathrm{~mA}$, and a field of view of $20 \mathrm{~cm}$. The presence of emphysema was defined as well- 


\section{Figure 1. A Flow Diagram of the Study Patients With COPD}

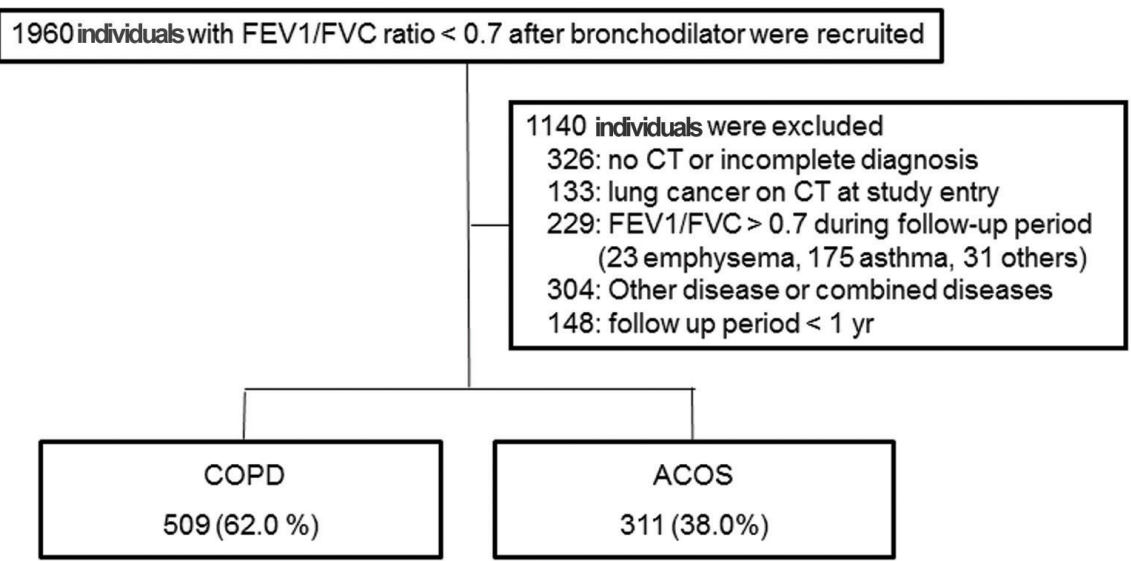

$\mathrm{FVC}=$ forced vital capacity; $\mathrm{FEV}_{1}=$ forced expiratory volume in one second; $\mathrm{CT}=$ computed tomography; $\mathrm{COPD}=$ chronic obstructive pulmonary disease; $\mathrm{ACOS}=$ asthma-COPD overlap syndrome. presence of asthma, age, pack years of smoking, current smoking, presence of chronic sputum, FVC, FEV 1 (measured as a percentage of the predicted value according to the guidelines of the Japanese Respiratory Society), ${ }^{21}$ airway reversibility with short acting beta2-agonist, BMI, use of inhaled corticosteroids (ICSs), and a history of pneumococcal vaccination. Using the variables identified by univariate analysis, we identified independent risk factors for pneumonia by a multivariate Poisson regression analysis demarcated areas in which attenuation was decreased in comparison to contiguous normal lung and marginated by a very thin wall (or no wall) with upper zone predominance. The presence of emphysema and the $\mathrm{CT}$ diagnosis were determined by 2 radiologists with extensive experience in the diagnosis of respiratory diseases; all were blind to the findings of the other researchers.

\section{Pulmonary Function Tests}

Pulmonary function tests (PFTs) were performed with a CHESTAC8800 (Chest MI Corp., Tokyo, Japan). Spirometry was performed according to the guidelines issued by the American Thoracic Society / European Respiratory Society, and the predicted values were derived from the Japanese Respiratory Society. ${ }^{20,21}$ Spirometry was performed before and 30 minutes after the inhalation of $200 \mu \mathrm{g}$ of salbutamol; the data obtained after the inhalation were used for the evaluation.

\section{Statistical Analysis}

Categorical baseline characteristics are shown as percentages, and continuous characteristics are reported as the mean \pm standard deviation (SD). Categorical values were compared using a chi-squared test or Fisher's exact test. Continuous variables were compared using the Mann-Whitney' U-test. Comparisons between subgroups of 3 or more groups were performed by Dunn's post-test after the Kruskal-Wallis test.

We first screened the following variables as possible risk factors for pneumonia by univariate analysis: with Firth's bias reduction. Regression analyses were analyzed with the SAS version 9.1.3 SP4 software program (SAS Institute Inc., Cary, North Carolina). Other analyses were performed using the Prism 5 software program (Graph Pad Software, Inc., La Jolla, California). $P$ values of $<0.05$ were considered to be statistically significant.

\section{Results}

The clinical characteristics of the patients are shown in Table 1. The mean observation period was 5.5 years. More than $80 \%$ of patients with ACOS had a history of smoking and $51.1 \%$ of patients with ACOS had emphysema on HRCT. There were no differences in the age and the pneumonia frequency between the COPD and ACOS groups. One hundred and fifty eight patients (19.3\%) received the PPV and another 662 were followed clinically.

In the total of 820 patients, 131 (16.1\%) patients had 199 episodes of pneumonia. The incidence of pneumonia (55.9 per 1000 patient-years) was compatible to those of previous studies of COPD patients (47-55 per 1000 patient-years). ${ }^{14,22}$ The causative bacteria were only recorded in 37 episodes of pneumonia (18.7\%). S. pneumonia was identified in 1 episode of pneumonia in the PPV group and 19 episodes of pneumonia in the noPPV group ( $p=0.077$, single-sided Fisher's test). Among the 114 deceased patients, 7 patients were found to have died from pneumonia, none of whom had received the PPV ( $p=0.222$, single-sided Fisher's test).

We evaluated the possible risks for pneumonia in 


\section{Table 1. Characteristics of the Patients With Chronic Airflow Obstruction}

\begin{tabular}{|c|c|c|c|c|}
\hline \multirow[b]{2}{*}{ Number } & Total & COPD & ACOS & \multirow[b]{2}{*}{$P$ Value } \\
\hline & 820 & 509 & 311 & \\
\hline Age (y) & $68.1 \pm 8.3$ & $69.2 \pm 7.9$ & $66.9 \pm 8.6$ & NS \\
\hline Emphysema (n, \%) & $581,70.9 \%$ & $422,82.9 \%$ & $159,51.1 \%$ & $<0.001$ \\
\hline Female Sex (n, \%) & $85,10.4 \%$ & $18,3.5 \%$ & $67,21.5 \%$ & $<0.001$ \\
\hline Body Mass Index & $21.7 \pm 3.7$ & $21.3 \pm 3.5$ & $22.4 \pm 3.8$ & $\mathrm{NS}$ \\
\hline Never Smoker (n, \%) & $60,7.3 \%$ & 0 & $60,19.3 \%$ & $<0.001$ \\
\hline Smoking Index (pack years) & $56.9 \pm 35.5$ & $66.7 \pm 33.7$ & $41.0 \pm 32.5$ & $<0.001$ \\
\hline \%FVC & $85.9 \pm 19.1$ & $85.7 \pm 19.3$ & $86.3 \pm 18.7$ & NS \\
\hline \%FEV 1 & $61.0 \pm 23.7$ & $60.9 \pm 24.3$ & $61.1 \pm 22.7$ & NS \\
\hline Vaccine (n, \%) & $158,19.3 \%$ & $95,18.7 \%$ & $63,20.3 \%$ & NS \\
\hline Inhaled Corticosteroid (n, \%) & $430,52.4 \%$ & $166,32.6 \%$ & $264,84.9 \%$ & $<0.001$ \\
\hline Observation Period (y) & $5.5 \pm 2.7$ & $5.0 \pm 2.6$ & $6.3 \pm 2.8$ & $<0.001$ \\
\hline \multicolumn{2}{|c|}{ Pneumonia/1000 Patients, year $55.9 \pm 179.0$} & $61.9 \pm 177.5$ & $47.0 \pm 181.2$ & $\mathrm{NS}$ \\
\hline
\end{tabular}

$\mathrm{COPD}=$ chronic obstructive pulmonary disease; $\mathrm{ACOS}=$ asthma-COPD overlap syndrome;

$\% \mathrm{FVC}=$ percent predicted forced vital capacity; $\% \mathrm{FEV}_{1}=$ percent predicted forced expiratory volume

in 1 second

a total of 820 patients. Pneumonia occurred almost equally in the patients who were treated with ICSs (55.3 per 1000 patient-years; 430 patients) and those who were not (56.4 per 1000 patient-years; 390 patients). Patients with chronic sputum (388 patients) had 56.9 cases of pneumonia per 1000 patient-years, whereas 53.7 pneumonia cases per 1000 patient-years occurred in patients without sputum (411 patients, NS). The univariate analysis revealed that age $(p=0.031), \% F V C(p<0.001), \% \mathrm{FEV}_{1}$ $(p<0.001)$, BMI $(p=0.003)$, emphysema $(p<0.001)$ and a history of pneumococcal vaccination $(p=0.034)$ were associated with the frequency of pneumonia. However, the presence of asthma was not associated with the frequency of pneumonia. To examine the independent risk factors for pneumonia, we subjected the above factors to a multivariate Poisson regression analysis. Low BMI, the presence of emphysema and the absence of pneumococcal vaccination were identified as the independent risk factors for pneumonia in patients with COPD including ACOS (Table 2).

As shown in Figure 2, patients with CT-diagnosed emphysema had a higher frequency of pneumonia than those without emphysema (69.6 per 1000 patient- years versus 23.5 per 1000 patient-years, respectively). When stratifying the study population by the median of BMI $\left(22 \mathrm{~kg} / \mathrm{m}^{2}\right)$ and $\% \mathrm{FEV}_{1}$ (60\%, predicted), patients with lower BMI $\left(<22 \mathrm{~kg} / \mathrm{m}^{2}\right)$ had a higher frequency of pneumonia than those with higher BMI $\left(\geq 22 \mathrm{~kg} / \mathrm{m}^{2}\right)$ (72.6 per 1000 patient-years versus 34.2 per 1000 patient-years, respectively), and patients with lower $\% \mathrm{FEV}_{1}(<60 \%$, predicted) had a higher frequency of pneumonia than those with a higher $\mathrm{FFEV}_{1}(\geq 60 \%$, predicted) (77.7 per 1000 patient-years versus 30.9 per 1000 patient-years, respectively). Vaccinated patients had a frequency of pneumonia of 28.4 cases per 1000 patient-years, while unvaccinated patients had a frequency of 62.4 cases per 1000 patient-years $(p=0.151)$.

The combined risk factors of low BMI and low \%FEV 1 have been reported to increase the risk of pneumonia in patients with COPD. ${ }^{3}$ Thus, we next calculated the effects of the combined risk factors for pneumonia, i.e., low BMI, $<22 \mathrm{~kg} / \mathrm{m}^{2}$ (B), low $\% \mathrm{FEV}_{1},<60 \%$ (O), a history of pneumococcal vaccination (V) and the presence of CT-diagnosed emphysema (E). As shown in Table 3, the combination of low BMI, low \%FEV 1 and the presence of emphysema increased the risk of pneumonia. The 


\section{Table 2. A Poisson Regression Analysis of Frequency of Pneumonia in COPD and Asthma-COPD Overlap Syndrome}

\begin{tabular}{|c|c|c|c|c|c|}
\hline & $\exp (\beta)$ & $\begin{array}{c}95 \% \text { Cl Lower } \\
\text { of } \exp (\beta)\end{array}$ & $\begin{array}{c}95 \% \text { Cl Upper } \\
\text { of } \exp (\beta)\end{array}$ & $\begin{array}{c}\text { Chi-Squared } \\
\text { Test }\end{array}$ & $P$ Value \\
\hline Age & 1.01 & 0.99 & 2.75 & 1.565 & 0.21 \\
\hline$\%$ FVC & 0.99 & 0.98 & 2.69 & 0.557 & 0.46 \\
\hline$\%$ FEV $_{1}$ & 0.98 & 0.98 & 2.69 & 1.912 & 0.17 \\
\hline BMI & 0.93 & 0.88 & 2.53 & 4.525 & 0.03 \\
\hline Emphysema(1/0) & 2.21 & N.D. & 9.12 & 6.604 & 0.01 \\
\hline Vaccine $(1 / 0)$ & 0.48 & 0.23 & N.D. & 6.599 & 0.01 \\
\hline
\end{tabular}

$\mathrm{COPD}=\mathrm{chronic}$ obstructive pulmonary disease; $\mathrm{ACOS}=$ asthma-COPD overlap syndrome; \%FVC=percent predicted forced vital capacity; $\% \mathrm{FEV}_{1}=$ percent predicted forced expiratory volume in 1 second; $\mathrm{BMI}=$ body mass index; $\mathrm{CI}=$ confidence interval

\section{Figure 2. Risk Factors for Pneumonia and the 23 Discussion} Serotype Pneumoccal Vaccine
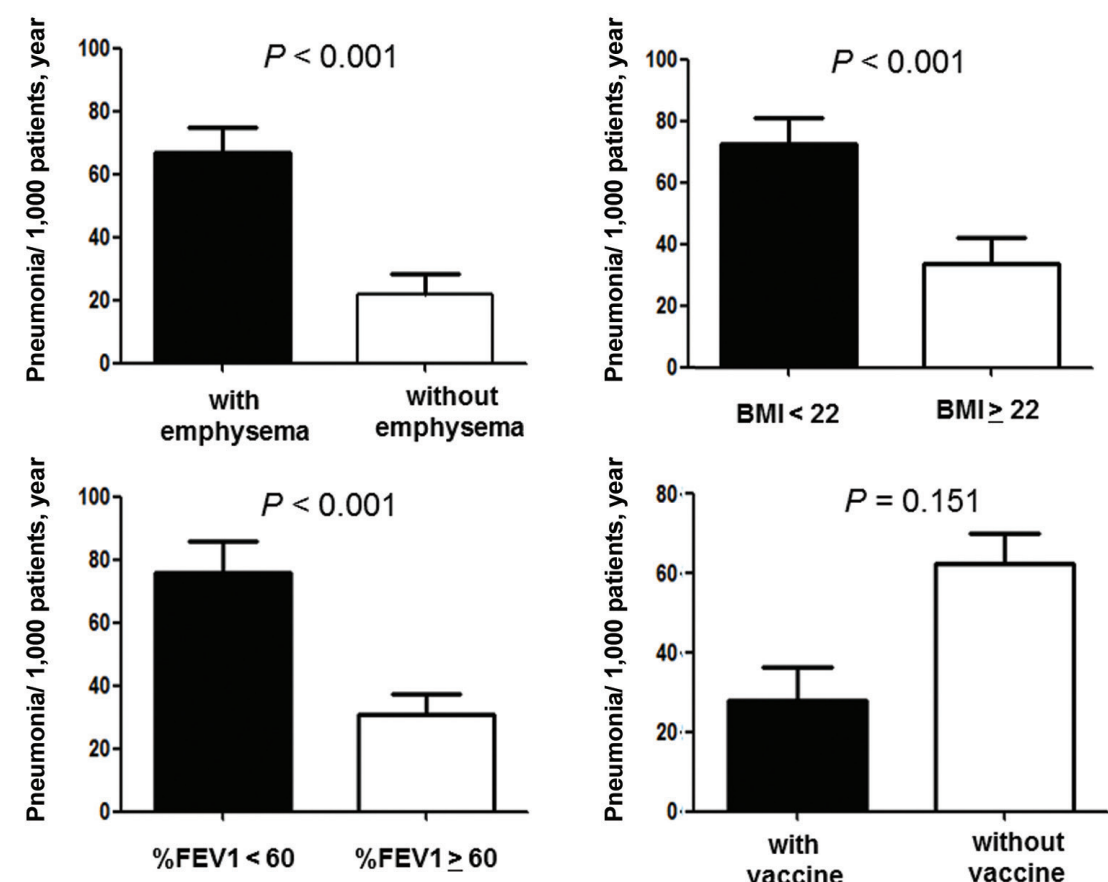

$\mathrm{BMI}<22 \quad \mathrm{BMI} \geq 22$

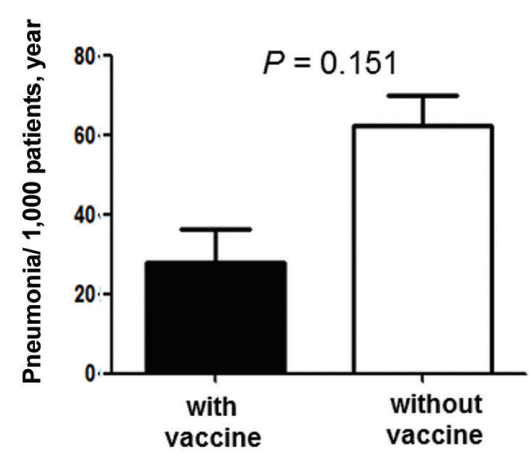

The effects of risk factors for pneumonia and the preventive effect of the 23 serotype pneumococcal vaccine against pneumonia in patients with COPD and asthma-COPD overlap syndrome.

$\mathrm{BMI}=$ body mass index; $\% \mathrm{FEV}_{1}=$ percent predicted value of forced expiratory volume in 1 second.
Patients with COPD and ACOS had similar clinical backgrounds in age, BMI, severity of airflow limitation and incidence of pneumonia. The results suggest that risk management for pneumonia should be considered similarly in patients with COPD and ACOS. We introduced a simple grading system for the assessment of pneumonia risk for COPD/ACOS: the BOVE index. It includes 4 independent components (low BMI, low $\% \mathrm{FEV}_{1}$, history of pneumococcal vaccination and emphysema), and we believe that it is useful for identifying high risk groups for pneumonia in COPD/ACOS patients. The presence of emphysema was the most significant risk factor for pneumonia and it cannot be modified. However, number of pneumonia events accumulated in the subgroups with more than 2 risk factors and/or the noPPV group. As shown in Figure 3, the combined BOVE risk index (the sum of $[B=1],[O=1],[V=-1]$, and $[E=1]$ ) was related to the frequency of pneumonia in patients with COPD. an important message of the BOVE system would be that pneumococcal vaccination is associated with a significant reduction in the incidence of overall pneumonia.

In 2000 , we began to consecutively register patients with CAO. These patients underwent diagnostic procedures and their prognoses were followed with appropriate care. $^{19}$ At almost the same time, we 


\section{Table 3. The Number of Risk Factors for Pneumonia and Pneumonia Events}

\begin{tabular}{|c|c|c|c|c|c|c|c|c|c|}
\hline & \multicolumn{2}{|c|}{ Patients } & \multicolumn{2}{|c|}{$\begin{array}{c}\text { Pneumonia } \\
\text { Events }\end{array}$} & & \multicolumn{2}{|c|}{ Vaccine } & \multicolumn{2}{|c|}{$\begin{array}{c}\text { Pneumonia } \\
\text { Events }\end{array}$} \\
\hline & $n$ & $\%$ & $n$ & $\%$ & & $n$ & $\%$ & $n$ & $\%$ \\
\hline \multirow[t]{2}{*}{ Risk 3} & \multirow[t]{2}{*}{221} & \multirow[t]{2}{*}{27.0} & \multirow[t]{2}{*}{103} & \multirow[t]{2}{*}{51.8} & no & 167 & 20.4 & 83 & 41.7 \\
\hline & & & & & yes & 54 & 6.6 & 20 & 10.0 \\
\hline \multirow[t]{2}{*}{ Risk 2} & \multirow[t]{2}{*}{266} & \multirow[t]{2}{*}{32.4} & \multirow[t]{2}{*}{70} & \multirow[t]{2}{*}{35.2} & no & 215 & 26.2 & 65 & 32.7 \\
\hline & & & & & yes & 51 & 6.2 & 5 & 2.5 \\
\hline \multirow[t]{2}{*}{ Risk 1} & \multirow[t]{2}{*}{233} & \multirow[t]{2}{*}{28.4} & \multirow[t]{2}{*}{20} & \multirow[t]{2}{*}{10.0} & no & 197 & 24.0 & 18 & 9.0 \\
\hline & & & & & yes & 36 & 4.4 & 2 & 1.0 \\
\hline \multirow[t]{3}{*}{ Risk 0} & \multirow[t]{2}{*}{100} & \multirow[t]{2}{*}{12.2} & \multirow[t]{2}{*}{6} & \multirow[t]{2}{*}{3.0} & no & 83 & 10.1 & 6 & 3.0 \\
\hline & & & & & yes & 17 & 2.1 & 0 & 0.0 \\
\hline & 820 & 100.0 & 199 & 100.0 & & 820 & 100.0 & 199 & 100.0 \\
\hline
\end{tabular}

Number of risks is the sum of following risk factors: body mass index $<22 \mathrm{~kg} / \mathrm{m}^{2}$, percent predicted forced expiratory volume in 1 second $<60 \%$, or the presence of computed tomography-diagnosed emphysema. Each of the groups was stratified by their history of vaccination with the 23-valent pneumococcal polysaccharide vaccine.

\section{Figure 3. The BOVE Index and the Frequency of Pneumonia in Patients With COPD}

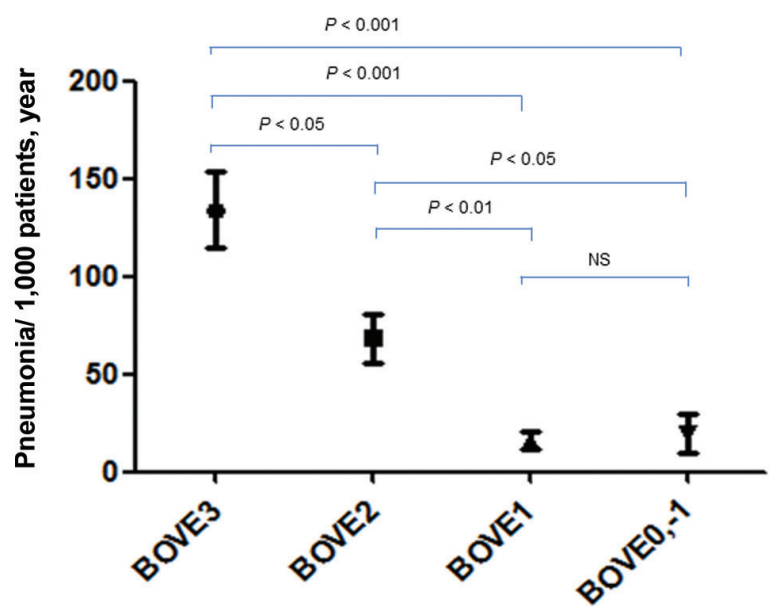

The BOVE combined risk index is the sum of the following factors: body mass index $<22 \mathrm{~kg} / \mathrm{m}^{2}$, $B=1$; percent predicted forced expiratory volume in 1 second $\angle 60 \%, 0=1$; history of pneumococcal vaccination, $v=-1$; and the presence of emphysema, $\mathbf{E}=1$. began to recommend that our patients with chronic respiratory diseases receive the PPV. During the time of this retrospective study, approximately $20 \%$ of the COPD patients at our clinic received the vaccination. The pneumococcal vaccination had not been used much in Japan before the government began financial support for the PPV in 2014. Since no attempt was made to allocate the vaccination to particular patients in this study, the bias from the patients' backgrounds would be limited. The patients who received vaccination were similar to the patients who did not receive it in age, BMI and emphysema. However, patients with the PPV had significantly lower $\% F^{2} V_{1}$ than those of the patients without vaccination $(56.7 \pm 21.8$ versus 61.9 \pm 24.0 , respectively, $p=0.020)$. Therefore, vaccination benefits shown in this study might be underestimated because of healthy user effect. ${ }^{23}$

One of the strengths of the present study is that extensive diagnostic tests were performed to rule out other diseases that may cause CAO. Among 1960 consecutive patients who showed airflow limitation that was not-fully reversible, 1140 patients were excluded by the initial differential diagnosis or through repeated examinations over years. It is considered that these diagnostic procedures clarified the cohort of COPD/ ACOS patients and allowed us to obtain reliable 
clinical parameters for the analysis. Another strength of the present study is that all 820 patients underwent HRCT, thus we were able to evaluate the significance of emphysema as a risk factor for pneumonia.

The current data is in accordance with the previous report by DiSantostefano et al who first demonstrated that the combination of low $\% \mathrm{FEV}_{1}$ and low BMI increased the risk of pneumonia in COPD patients. ${ }^{3}$ Another study also linked low $\% \mathrm{FEV}_{1}$ to pneumonia. ${ }^{14}$ Based on these previous reports and our results, we created the BOVE index, which used the combination of low BMI $(B=1)$, low $\% F V_{1}(O=1)$, a history of pneumococcal vaccination $(\mathrm{V}=-1)$ and $\mathrm{CT}$-diagnosed emphysema $(E=1)$, to predict the risk for pneumonia in patients with COPD/ACOS. The index gave equal weighting to these variables for simplicity in clinical practice. In addition, we consider that different weighting of the variables would not improve the predictive power of the BOVE index because the incidence ratio for each factor was within 2.1-2.9.

In this study, the CT-diagnosed emphysema was the strongest risk factor for pneumonia among all of the clinical parameters in patients with COPD/ACOS. Eom et al reported that the presence of emphysema was associated with severity of pneumonia in 148 pneumonia patients with COPD. ${ }^{24}$ Recently, we demonstrated that lower-lobe emphysema was most strongly associated with exacerbation frequency within the COPD lung structures such as the airway diameters. ${ }^{25}$ These reports suggest that CT evaluation of emphysema is useful to predict risk and severity of pneumonia in patients with COPD.

There are reports that certain ICSs increase the risk for pneumonia in patients with COPD. ${ }^{26-28}$ However, we did not observe any difference in the frequency of pneumonia by the use of ICSs. Possible explanations of this result would be the size of this study and dosage of ICS used in this study. In Japan, high-dose ICS (frucicasone 500 $\mathrm{gg}$, twice per day or budesonide $>320 \mu \mathrm{g}$, twice per day) is not used to treat patients with COPD. ${ }^{16}$

The evidence of a protective effect of a 23 serotype PPV for patients with COPD is limited. A randomized controlled trial was carried out in 596 patients with COPD however, the Kaplan-Meier survival curves for CAP did not show a significant difference between the patients who received the PPV and the nonintervention group. The PPV was only effective in patients with COPD who were younger than 65 years of age and in patients with severe airflow limitation. ${ }^{14}$ Leech et al administered a 14-serotype PPV in patients with airflow limitation, but did not observe a significant difference between the groups in the 2-year follow-up, partly because the low rate of pneumococcal bacteremia. ${ }^{29}$ Our retrospective cohort study suggests that it would be difficult to prove effectiveness of the PPV in a simple randomized study because the frequency of pneumonia is low and episodes of pneumonia accumulated in the subgroups with certain risk factors. The present study was able to show that PPV administration was associated with a significantly low incidence of pneumonia in patients with COPD/ACOS. It is noteworthy that none of the vaccinated patients died from pneumonia during the observational period. Gómez-Junyent et al recently reported in a large study that pneumococcal vaccine reduced the risk of mortality in pneumonia patients with COPD. ${ }^{30}$

The present study is associated with the following limitations. As discussed above, this study was retrospective in nature and the vaccinations were not randomized. However, we recommended vaccination to the patients with chronic respiratory disease per guidelines, ${ }^{31}$ so that there was no doctor-sided selection bias. Another limitation of the present study is that the etiological bacteria were not assessed due to the limited available data. The cut-off levels of $\% \mathrm{FEV}_{1}$ and BMI may change based on certain patient background characteristics, such as race or country. In addition, we did not have data of prior pneumonia or exacerbations before the start of the observation period. Among 42 patients who experienced more than 2 pneumonias during the observation period, 11 patients were in BOVE 3 (26.2\%) and 17 patients were in BOVE 2 (40.5\%). Therefore, two thirds of the patients who experienced repeated pneumonias were included in higher risk categories. Finally, one third of the COPD patients in this study had ICS usage. It might be low when compared to international standards. However, the Japanese COPD guidelines do not strongly recommend ICSs unless the patient has repeated exacerbations, an asthma component or late stage airflow limitation. ${ }^{16}$ In addition, incidence of exacerbations is relatively low in Japan. ${ }^{32}$

In conclusion, the BOVE index is simple and is able to predict the high risk group for pneumonia in patients with COPD/ACOS. It emphasizes 3 independent risk factors (low BMI, low $\% \mathrm{FEV}_{1}$, emphysema) and shows 
how the PPV reduces the impact of these risks. It will be useful to encourage patients to receive the PPV, for the management of patient health care and for the patient allocation in future clinical trials.

\section{Acknowledgements}

Author contributions: Kazuyoshi Kurashima was the principal investigator/corresponding author/ guarantor. Yotaro Takaku, Keitaro Nakamoto, Tetsu
Kanauchi, Noboru Takayanagi, Tsutomu Yanagisawa, and Ryuichiro Araki were all contributing authors. Yutaka Sugita, provided advice and guidance.

\section{Declaration of Interest}

None of the authors have any real or apparent conflicts of interest, including no financial or consulting relationships, to disclose. 


\section{References}

1. Restrepo MI, Mortensen EM, Pugh JA, Anzueto A. COPD is associated with increased mortality in patients with communityacquired pneumonia. Eur Respir J. 2006;28(2):346-351. doi: http://dx.doi.org/10.1183/09031936.06.00131905

2. Müllerova H, Chigbo C, Hagan GW, et al. The natural history of community-acquired pneumonia in COPD patients: a population database analysis. Respir Med. 2012; 106(8): 11241133. doi: http://dx.doi.org/10.1016/j.rmed.2012.04.008

3. DiSantostefano RL, Li H, Hinds D, Galkin DV, Rubin DB. Risk of pneumonia with inhaled corticosteroid/long-acting beta 2 agonist therapy in chronic obstructive pulmonary disease: a cluster analysis. Inter Nat J COPD. 2014; 9(1): 457-468. doi: http://dx.doi.org/10.2147/copd.s60498

4. Silva GE, Sherrill DL, Guerra S, Barbee RA. Asthma as a risk factor for COPD in a longitudinal study. Chest. 2004; 126(1): 5965. doi:http://dx.doi.org/10.1378/chest.126.1.59

5. Global initiative for chronic Obstructive Lung Disease (GOLD). Diagnosis of diseases of chronic airflow limitation: asthma COPD and asthma-COPD overlap syndrome (ACOS), 2014. GOLD website. http://www.goldcopd.org/. Published 2014. Accessed: January 10, 2015.

6. Gibson PG, Simpson JL. The overlap syndrome of asthma and COPD: what are its features and how important is it? Thorax. 2009; 64 (8): 728-735.

doi: http://dx.doi.org/10.1136/thx.2008.108027

7. Abramson MJ, Schattner RL, Sulaiman ND, Del Colle EA, Aroni R, Thien F. Accuracy of asthma and COPD diagnosis in Australian general practice: a mixed methods study. Prim Care Respir J. 2012; 21:167-173.

doi: http://dx.doi.org/10.4104/pcrj.2011.00103

8. Soler-Catalu-a JJ, Cosío B, Izquierdo JL, et al. Consensus document on the overlap phenotype COPD-asthma in COPD. Arch Bronconeumol. 2012; 48(9): 331-337.

doi: http://dx.doi.org/10.1016/j.arbr.2012.06.017

9. Torres A, Dorca J, Zalacaín R, et al. Comminity-acquired pneumonia in chronic obstructive pulmonary disease. A Spanish multicenter study. Am J Respir Crit Care Med. 1996; 154(5): 1456-1461. doi: http://dx.doi.org/10.1164/ajrccm.154.5.8912764

10. Fine MJ, Smith MA, Carson CA, et al. Efficacy of pneumococcal vaccination in adults. A meta-analysis of randomized controlled trials. Arch Intern Med. 1994; 154(23): 2666-2677. doi: http://dx.doi.org/10.1001/archinte.1994.00420230051007

11. Jackson LA, Janoff EN. Pneumococcal vaccination of elderly adults: new paradigms for protection. Clin Infect Dis. 2008; 47(10): 1328-1338. doi: http://dx.doi.org/10.1086/592691
12. Shapiro ED, Berg AT, Austrian R, et al. The protective efficacy of polyvalent pneumococcal polysaccharide vaccine. $N$ Eng J Med. 1991; 325: 1453-1460.

doi: http://dx.doi.org/10.1056/NEJM 199111213252101

13. World Health Organization (WHO). 23-valent pneumococcal polysaccharide vaccine: WHO position paper. WHO website. http://www.who.int/wer/2008/wer8342.pdf Published October 2008. Accessed. January 2016.

14. Alfageme I, Vazquez R, Reyes N, et al. Clinical efficacy of antpneumococcal vaccination in patients with COPD. Thorax. 2006; 61(3): 189-195. doi: http://dx.doi.org/10.1136/thx.2005.043323

15. Kawakami K, Ohkusa Y, Kuroki R, et al. Effectiveness of pneumococcal polysaccharide vaccine against pneumonia and cost analysis for the elderly who receive seasonal influenza vaccine in Japan. Vaccine. 2010; 28(43): 7063-7069. doi: http://dx.doi.org/10.1016/j.vaccine.2010.08.010

16. Japanese Respiratory Society. Guidelines for diagnosis and management of COPD (chronic obstructive pulmonary disease), third edition: therapy and management. Ann Jpn Respir Society [Japanese]. 2009; Suppl COPD: 70-144.

17. Global initiative for chronic Obstructive Lung Disease (GOLD). Global Strategy for the Diagnosis, Management and Prevention of COPD, 2011. GOLD website. http://www.goldcopd.org/. Published 2011. Accessed: March 7, 2014.

18. Butler JC, Breiman RF, Campbell JF, Lipman HB, Broome CV, Facklam RR. Pneumococcal polysaccharide vaccine efficacy: An evaluation of current recommendations. JAMA. 1993; 270: 18261831.

doi: http://dx.doi.org/10.1001/jama.1993.03510150060030

19. Kurashima K, Fukuda C, Nakamoto K, et al. CT diagnosed emphysema and prognosis of chronic airflow obstruction: retrospective study. BMJ Open. 2013; 3: e003541. doi: http://dx.doi.org/10.1136/bmjopen-2013-003541

20. Miller MR, Hankinson J, Brusasco V, et al. Standardisation of spirometry. Eur Respir J. 2005; 26(2): 319- 338. doi: http://dx.doi.org/10.1183/09031936.05.00034805

21. Japanese Respiratory Society. The predicted values of spirometry and arterial blood gas analysis in Japanese[Japanese]. J Jpn Resp Soc. 2001; 39: Appendix.

22. Davis LA, Aranda CAP, Schiffman G, et al. Pneumococcal infection and immunologic response to pneumococcal vaccine in chronic obstructive pulmonary disease. Chest. 1987; 92 (2): 204-212. doi: http://dx.doi.org/10.1378/chest.92.2.204

23. Jackson LA, Nelson JC, Benson P, et al. Functional status is a confounder of the association of influenza vaccine and risk of all cause mortality in seniors. Int J Epidemiology. 2006; 35: 345-352. doi: http://dx.doi.org/10.1093/ije/dyi275 
24. Eon JS, Song WJ, Yoo H,et al. Chronic obstructive pulmonary disease is associated with severe pneumonia. Ann Thoracic Med. 2015; 10(2): 105-111.

doi: http://dx.doi.org/10.4103/1817-1737.151441

25. Kurashima K, Takaku Y, Hoshi T, et al. Lobe-based CT assessment of airway diameter, airway or vessel number and emphysema extent in relation to the clinical outcomes of COPD. Int J Chron Obstruct Pulmon Dis. 2015; 10: 1027-1033. doi: http://dx.doi.org/10.2147/COPD.S81748

26. Kew KM, Seniukovich A. Inhaled steroids and risk of pneumonia for chronic obstructive pulmonary disease. Cochrane Database of Systematic Reviews. 2014; (3). http://dx.doi. org/10.1002/14651858.CD010115.pub2

27. Singh S, Amin AV, Loke YK. Long-term use of inhaled corticosteroids and the risk of pneumonia in chronic obstructive pulmonary disease: a meta-analysis. Arch Intern Med. 2009; 169 (3): 219-229.

doi: http://dx.doi.org/10.1001/archinternmed.2008.550

28. Janson C, Larsson K, Lisspers KH, et al. Pneumonia and pneumonia related mortality in patients with COPD treated with fixed combinations of inhaled corticosteroid and long acting beta2 agonist: observational matched cohort study (PATHOS). BMJ. 2013; 346: f3306.

doi: http://dx.doi.org/10.1136/bmj.f3306

29. Leech JA, Gervais A, Ruben FL. Efficacy of pneumococcal vaccine in severe chronic obstructive pulmonary disease. Can Med Assoc J. 1987; 136: 361-365.

30. Gómez-Junyent J, Garcia-Vidal C, Viasus D, et al. Clinical features, etiology and outcomes of community-acquired pneumonia in patients with chronic obstructive pulmonary disease. PLOS ONE. 2014; 9: e105854.

doi: http://dx.doi.org/10.1371/journal.pone.0105854

31. Prevention of pneumococcal disease: recommendations of the Advisory Committee on Immunization Practice (ACIP). MMWR Recomm Rep. 46(RR-08): 1-24, 1997.

32. Suzuki M, Makita H, Ito YM, et al. Clinical features and determinants of COPD exacerbation in the Hokkaido COPD cohort study. Eur Respir J. 2014; 43(5): 1289-1297.

doi: http://dx.doi.org/10.1183/09031936.00110213 